\title{
'Toned habitus', self-emancipation and the contingency of reflexivity: A life story study of working-class students at elite universities in China
}

Jin Jin $^{\text {a*}}$, Stephen J. Ball ${ }^{\mathrm{b}}$

${ }^{a}$ Faculty of Education, East China Normal University, Shanghai, China; ${ }^{b}$ Department of Education, Practice and Society, UCL Institute of Education, London, UK

Jin Jin, corresponding author, post-doctoral researcher at the Faculty of Education, East China Normal University; postal address: Humanities Building, 3663 North Zhongshan Road, Shanghai 200062, China; telephone: +86 15618259082; email: jiin@dedu.ecnu.edu.cn

Stephen J. Ball, Distinguished Service Professor of Sociology of Education at UCL Institute of Education; postal address: Department of Education, Practice and Society, UCL Institute of Education, London WC1H 0AL, UK; telephone: +44 20 76793015; email: stephen.ball@ucl.ac.uk 


\title{
'Toned habitus', self-emancipation and the contingency of reflexivity: A life story study of working-class students at elite universities in China
}

\begin{abstract}
: studies in relation to working-class students at elite universities document on the one hand the role of 'mundane reflexivity' in dealing with class domination while on the other indicate a new form of domination and disadvantages working on these working-class 'exceptions' - they may achieve academically at university but experience various exclusions and self-exclusions in areas of social life. By drawing on a very small sample of 'counter-evidence' and 'exceptions within exceptions' - working-class students who achieve great social accomplishments at elite universities - this paper further explores the role of 'mundane reflexivity' in negotiating class domination and the possibilities of transcendence. We demonstrate the creative and transformative ways in which class domination is dealt with and document the prevalence of high-level reflexivity. Furthermore, we distinguish different forms and degrees of reflexivity, which then indicate the 'contingency' of reflexivity - the relation of the possibilities of reflexivity to the unequal distribution of social, cultural and economic capitals. We further argue that what appears to be a form of selfemancipation achieved by the 'transcending group' in our study also involves the discrete and insidious reproduction of social inequality.
\end{abstract}

Keywords: reflexivity and habitus; working-class 'exceptions'; 'toned habitus'; self-emancipation; contingency of reflexivity

Word count: 9,191 words (including the abstract and references) 


\section{Introduction: is it possible to transcend class domination?}

Class inequality has been extensively and exhaustively researched and discussed in sociological studies of education. A significant sub-set of these studies has discussed forms of exclusion and self-excluding mechanisms that bear upon the educational experiences and life chances of working-class students (e.g., Bourdieu and Passeron, 1990; Lareau, 2011; Putnam, 2015) and especially their unequal access to elite or selective schools and universities (e.g., Karabel, 2005; Reay et al., 2005; Zimdars, 2016). Although much of the current literature focuses on the patterns and consequences of the seemingly inexorable processes of class domination in different countries, a few authors (e.g., Aries and Seider, 2005; Authors, 2018; Granfield, 1991; Hurst, 2010; Lehmann, 2013; Reay et al., 2009; Xie, 2016) address the experience of 'deviants' (Bourdieu, 1996) or 'exceptions' (Wacquant, 1993) to the workings of social reproduction - working-class students who achieve school success against all the odds and gain entry into elite universities. Studies that do have such a focus indicate the possibilities of 'mundane reflexivity' (Sayer, 2005) and the existence of spaces within which the subjects of domination are able to negotiate with the processes of domination and to achieve changes and challenges to the consequences. Even with deficiencies in their family capitals, and in some cases despite unsupportive working-class schooling, some working-class students develop a set of 'internal resources' (Reay, et al., 2009, p.1107) - resilience, industry, determination, self-regulation and the ability to cope with adversity, among others - and they draw on these to achieve school success and to 
successfully adapt to and navigate their experience of the elite university (Jack, 2016; Lehmann, 2009; Postiglione et al., 2017; Reay et al., 2009).

However, such negotiations and the reflexive responses of working-class 'exceptions' to class domination are not entirely liberating and transcending: they are bound up with the limited external resources such 'exceptions' can draw on and they continue to be constrained and in part consumed by their working-class habitus (Authors, 2019a). The current literature in relation to the university experience of working-class 'exceptions' documents new forms of disadvantage and class domination - wherein they may achieve academically at university but they experience social exclusions and self-exclusions in terms of things like extra-curricular activities and career-relevant internships (e.g., Bathmaker et al., 2013; Stuber, 2011; Tomlinson, 2008; Xie et al., 2018). Indeed, the reflexive dispositions on which working-class 'exceptions' draw to achieve school success and that enable them to gain entry into elite universities are excessively orientated to academic performance and almost entirely neglect the accumulation of skills related to wider social and cultural experiences (Bourdieu and Passeron, 1990; Reay et al., 2009; Xie, 2016). This trajectory of school success is distinctly different from what Lareau (2011) calls 'concerted cultivation' the ways middle-class students secure school success by drawing in systematic and planned fashion on different forms of family capitals and by engaging in structured extra-curricular activities. Their lack of relevant economic and social capitals (Bathmaker et al., 2013; Lehmann, 2012), their self-excluding tendency to define themselves as 'unfit' ( $\mathrm{Li}, 2013$; Xie, 2016), a form of proactive social distancing 
motivated by loyalty to working-class values and community (Friedman, 2016; Reay et al., 2009) and deliberate social boundary building by different social classes (Keane, 2011) form further external and internal barriers to the fostering by working-class 'exceptions' of social accomplishments at university. Yet, as greater attention and emphasis are put on 'soft-credentials' (Tomlinson, 2008) and valuable 'personal capital' (Brown et al., 2011) as necessary additions to an elite degree by high-status employers, working-class 'exceptions' who experience university predominantly in academic terms may find it difficult to turn their paper qualifications into real opportunities for upward social mobility.

Contrary to findings documented in the current literature and based on six cases from a life story study conducted in China (details will be discussed later), this paper offers an account of how some working-class students thrive socially at elite universities. An analysis of the role of reflexivity in response to class domination is presented and different forms and degrees of reflexivity are distinguished and highlighted - 'reflexive awareness' versus 'post-reflexive' action (Adams, 2006) and 'adaptive reflexivity' versus 'transcending reflexivity'. Our main focus is on what we call a transcending group of working-class students, and our findings indicate a further set of relationships between reflexivity and capitals and social inequality - which we refer to as the 'contingency' of reflexivity - and shed light on a very nuanced form of social reproduction. We argue that this demonstrates the persistence and effectiveness of class domination and the difficulties of challenging it at an individual level. 


\section{Theoretical debate: 'reflexivity versus habitus' or 'reflexive habitus'}

We use Bourdieu's theoretical tool, habitus, together with field and capital, to work with our data. Yet, by operationalising habitus in an empirical study of a group of working-class students who seem to have countered the effects of habitus, at least to some degree, we aim to work on habitus by working with it and to achieve a more flexible, dynamic and fluid conceptualisation of the concept that can better accommodate, explain and understand reflexivity, change and transformation if possible.

Habitus is a sensitive and powerful tool for understanding the experience of class and social production and reproduction. It addresses how social inequalities are deeply embodied and how this embodiment contributes to the maintenance and reinforcement of inequalities. Habitus is 'systems of durable, transposable dispositions' which are produced in 'a particular class of conditions of existence' (Bourdieu, 1990, p.53). Dispositions include 'thoughts, perceptions, expressions and actions' (Bourdieu, 1990, p.55) and also 'bodily hexis', that is 'a durable way of standing, speaking, walking, and therefore feeling and thinking' (Bourdieu, 1990, p.70).

As we argue elsewhere (Authors, 2018), habitus has 'external contingency' in relation to field and capital and 'internal contingency' which tends to ensure its continuities and constancy. 'A particular class of conditions of existence' (economic and social conditions of family and family relations) produces 'structured structures' in habitus as principles to 'generate and organise practices and representations' (Bourdieu, 
1990, p. 53). Also, the embodiment of certain dispositions requires possession of certain forms of capital, as Bourdieu (1990, p.64) illustrates below. The possession of capitals, in different volumes and forms, that is, different class positions, contribute to different 'structured structures' in the habitus and in classed dispositions.

The 'rational' habitus which is the precondition for appropriate economic behaviour is the product of particular economic condition, the one defined by possession of the economic and cultural capital required in order to seize the potential opportunities theoretically available to all.

There is 'ontological complicity' (Bourdieu and Wacquant, 1992) between habitus and field, which grants some groups 'taken for granted' advantages and brings the other groups 'misadaptation' and 'revolt' (Bourdieu, 1990, p.62). Habitus can objectively adapt to fields that are identical to its 'primary conditioning' (Bourdieu, 1990, p. 62), 'without presupposing a conscious aiming at ends' (Bourdieu, 1990, p.53), the actor is like a 'fish in water' (Bourdieu and Wacquant, 1992, p.127). Meanwhile, habitus can also 'outlive the economic and social conditions in which they were produced' (Bourdieu, 1990, p.62) and 'function out of phase' (Bourdieu, 1990, p.62) in fields that are different from its primary conditioning. Studies in relation to various forms of 'habitus dislocation' experienced by working-class students at elite universities (e.g., Aries and Seider, 2005; Li, 2013) have vividly described 'the effects of primary conditioning' (Bourdieu, 1990, p.62) in maintaining social distinctions and inequalities. Furthermore, habitus has 'internal contingency' that ensures continuities and constancy. Although habitus has 'infinite capacity for generating products' (Bourdieu, 
1990, p.55) and is permeable to and restructured by new experiences (Reay, 2004), the 'structuring' and 'restructuring' of habitus is set within and formed by 'class frames of references' (Lauder and Hughes, 1999, p.27). Habitus is inculcated 'possibilities and impossibilities', 'opportunities and prohibitions' (Bourdieu, 1990, p.54) and classifications and categories of 'the possible (for us) and the impossible (for us)' (Bourdieu, 1990, p.64). Through choices 'to refuse what is anyway denied and to will the inevitable' (Bourdieu, 1990, p.54), 'the most improbable practices are therefore excluded, as unthinkable' (Bourdieu, 1990, p.54). Crisis is avoided and a 'probable future' (Bourdieu, 1990, p.64) is achieved. Through the unconscious but persistent operation of habitus, the dominated 'become the accomplices of the processes that tend to make the probable a reality' (Bourdieu, 1990, p.65) and themselves maintain and reinforce the inequalities and forms of domination in and through which they live.

In Bourdieu's scheme, with its emphasis on the effects of primary conditioning and the unconscious fulfilment of 'social class in head' (Ball et al., 2002, p.52), the notion of habitus seems to ignore the role of the 'intelligence' (Rancière, 1991) and 'critical capabilities' (Boltanski and Chiapello, 2007) of the dominated in responding to domination. While Bourdieu offers much empirical evidence of reflexivity in The Weight of the World (1999a), he does not address 'mundane reflexivity' (Sayer, 2005) theoretically and adequately in his work. This lack of discussion on reflexivity constrains the explanatory power of habitus and appears to leave the notion of habitus as essentially deterministic. Some authors (e.g., Abrahams and Ingram, 2013; Ingram, 2011; Reay, 2004; Reay et al., 2009; Sayer, 2005) have made attempts to 'hybridize 
habitus and reflexivity' (Adams, 2006). We argue that these attempts are mainly based on two approaches: 'reflexivity versus habitus' and 'reflexive habitus'.

The 'reflexivity versus habitus' approach argues for the existence of a 'presocial' (Gronow, 2008, p.245) self, which is 'part of humanity', 'prior and primitive to our sociality' (Archer, 2000, p.121) and which is capable of developing 'internal conversation' with our social self (Sayer, 2005), thus facilitating reflexive responses to domination and enabling changes and challenges to class reproduction. Further, social actors do not only make classifications of the possible and the impossible, they also, as Sayer (2005) argues, 'actively discriminate between the good and the bad' (p.34) and moreover they have a 'desire for recognition and self-respect' (p.35). As a consequence, he suggests, a 'probable future' can be refused and what is refused can be longed for. The agenda of pre-social reflexivity confirms the 'intelligence' of the dominated, but the claim for a pre-social reflexivity as part of humanity obscures the relation of capital and field to the development of such forms of reflexivity and hides unequal distribution of opportunities for the maintenance and cultivation of these reflexive dispositions. As will be seen later in this paper, such opportunities to maintain and develop reflexivity are bound up with unequal power relationships.

'Reflexive habitus', on the contrary, emphasises the role of practice and socialisation experiences in forming reflexivity and explains reflexivity as a response of habitual dispositions to 'crisis situations' - the disjunctures between habitus and field. Those who experience such habitus dislocations and movements between social fields may develop a particular self-awareness that engenders a set of reflexive dispositions 
(Abrahams and Ingram, 2013; McNay, 1999; Reay et al., 2009; Sweetman, 2003). However, as argued by some authors (Adams, 2006; Adkins, 2002), reflexive dispositions, such as self-awareness or self-dependent dispositions that are learnt from the experiences of dealing with crisis situations, do not 'equate with the ability to transform one's situation' (Adams, 2006, p.522). As shown by the university experience of most of our respondents (Authors, 2019a), reflexivity does not in itself enable choice, indeed 'just a painful awareness of the lack of it' (Adams, 2006, p.523). In this paper, we highlight what might be called the 'intelligence' of the dominated and their capability for reflexivity and indicate some of the creative and transformative ways in which they are able to challenge class domination, as the 'reflexivity versus habitus' position suggests, but also, we indicate the continuing relation of capitals and social inequality to the possibilities of reflexivity. Furthermore, we demonstrate how reflexivity is practised and engrained into habitus, evolving into what we call a 'toned habitus' that enables working-class students to achieve a certain degree of transcendence of class domination and 'self-emancipation' (Giroux, 1983, p.290). As we understand habitus, we point to the external and internal 'contingency' of reflexivity and demonstrate the transformative and reproductive aspects of reflexivity. Reflexivity is then a kind of 'conditioned and conditional freedom' (Bourdieu, 1990, p.55); it challenges certain forms of class domination but brings into play domination in another and a more nuanced form. 


\section{The context and the research method: possibilities to generate reflections on different relations between domination and reflexivity}

We introduce the class perspective and class analysis tools to a relatively new context in terms of researching class domination in education - the People's Republic of China - where the discourse of class is infrequently addressed and indeed overshadowed by a highly individualistic and meritocratic culture and history (Bell 2016; Elman 2013). It is within this meritocratic setting that we seek to shed light on the 'interacting relations between dominance and autonomy' (Giroux, 1983, p.290) and highlight a new and subtle form of class domination confronted by working-class 'exceptions', one that is related to and mediated by meritocratic disciplines (see the details of this form of class domination later in this section and in Authors, 2019b).

The data of this paper comes from a life story study conducted between March, 2015 and December, 2017. Three-rounds of life story interviews were conducted with 17 working-class students at four elite universities in China: Fudan University, Peking University, Shanghai Jiao Tong University and Tsinghua University. These four elite universities were chosen from the C9 League, the nine prestigious universities in China which are selected to receive the largest amount of government funding as a means to build an elite group of world-class universities. They recruit the highest-achieving students in the national college entrance examination ${ }^{1}$, and they are all located in Beijing and Shanghai, the two biggest cities in China with similar economic, social and

\footnotetext{
${ }^{1}$ Sources from the Ministry of Education: http://www.cdgdc.edu.cn/xwyyjsjyxx/xwsytjxx/yxmd/274942.shtml .
} 
cultural resources. Participants were recruited from final year undergraduate students who had received National Student Loans (needs-based loans for low-income students at university) and we checked their parents' occupations, income and education levels, their place of birth and their self-identification in the interviews in order to 'verify' their working-class status. These accounts were also compared with national statistics and with studies in relation to the social class structure in China ( $\mathrm{Li}$ and Qin, 2016; Liu, 2018; Lu, 2002). The occupations of our respondents' parents (with only two exceptions $^{2}$ ) are in the tiers below the 'middle-class' (Liu, 2018; Lu, 2002), which include the unemployed, peasants, factory workers, service workers and small business owners.

We adopt a class perspective rather than the rural/urban perspective that is commonly used in academic studies in China and in the lexicon of policies addressing educational inequalities in China. Although we are aware of the vast inequalities associated with the rural/urban divide in China (in fact some evidence related to consequences of this divide is reported in this paper), by introducing a class perspective, we want to give voice to those socially disadvantaged urban students whose plight has

\footnotetext{
2 Of the two exceptions (Xiang He and Yifan Yang; the latter is one of the six cases that are discussed in this paper) as 'working-class' according to their parents' occupations, but both of these exceptions come from the 'national deprived towns' (their own description; Yifan Yang moved to the city during primary school as his father changed job) and their reported parental income is way below the national average. Also, their life stories demonstrate various forms of constraint arising from capital deficits and they self-define as 'definitely working-class'. For these reasons we include them in our sample but define them as 'upper working-class'. By including these two cases, we want to explore varied experiences between class fractions. Some of the differences in their experiences from other respondents can be seen in the section on 'toned habitus' in this paper.
} 
been neglected by policy. Also, we want to draw attention to a broader range of mechanisms of exclusion that produce and reproduce social inequalities in China apart from the rural/urban divide. To do this we deploy 'western' class analysis tools, which then enable us to explore some less obvious and visible forms of class domination, such as those realised within emotional politics (Skeggs, 1997) and various forms of symbolic violence (Bourdieu, 1990). The effectiveness of using 'western' class tools to study social inequalities in China has been indicated by some previous studies (e.g., Li, 2013; Xie et al., 2018). Nevertheless, we are very aware of the particularities of the Chinese context when we use the notion of social class and class analysis tools. Social class does carry different meanings - where the class structure and class distinctions are still evolving. Examples of such differences have been discussed elsewhere (Authors, 2019a, p.4). Considering the particularities of the Chinese context, we use 'Informed Grounded Theory' approach (Thornberg, 2012) in the data analysis, with the data and the context always prioritised and 'western' class analysis tools only deployed reflexively, where necessary and appropriate, to establish dialogue with the literature, challenge our 'biases' and extend our 'sociological gaze' (Bourdieu and Wacquant, 1992, p.36).

Indeed, based on the highly individualistic and meritocratic national context, we demonstrate a complex relationship between meritocracy, social mobility and class domination, and discuss a new form of class domination, which is mediated and obscured by meritocracy (see the definition of meritocracy and its relation to social inequality and class domination in Authors, 2019b). Without the requisite capitals in 
the working-class position, the working-class 'exceptions' have to subject to meritocratic disciplines at school and invest heavily in meritocratic dispositions (e.g., hard work, self-discipline, performance-orientated flexibility and reflection) to ensure excellent examination performance in order to achieve social mobility. This way of achieving school success, systematically ignoring the accumulation of experience and skills in social and cultural activities, distances them from middle-class students and the middle-class sensibilities to which they aspire, as they continually leave behind and distance themselves from their working-class families and origins. They experience a 'double isolation' from both 'their origin and destination class' (Friedman, 2016, p.132) and they are singled out by their school success as a 'third class' (the position of being caught between the working-class and the middle-class; see also 'social limbo' in Friedman, 2016 and 'a third space' in Abrahams and Ingram, 2013) with core values and dispositions embedded in meritocracy. Furthermore, the everyday practices in schools (e.g., monthly rankings of performance, boarding school arrangements and the omission of music and art classes) and the meritocratic structure in the Chinese education system (examination performance based selection and progression into elite schools and elite universities) reinforce the two-sided distancing of working-class 'exceptions' and their meritocratic values. Through the synthesis between their individual pursuit of social mobility and institutional discipline at elite schools, these working-class 'exceptions' are trained and transformed into 'one dimensional' boys and girls (Marcuse, 1991) whose self-worth, identification, imagined futures and possibilities are produced and limited within the meritocratic imaginaries. These 
working-class 'exceptions', who appear to escape a 'probable future' predicted by their class position, fall into another 'probable future' which is regulated by meritocracy. They do not transcend their class origins, but they are subject to another form of class domination, one obscured by meritocratic disciplines.

For most of our respondents (11/17; see Authors, 2019a), their university experience does little to alter the consequences of their subjection to meritocratic disciplines and the related form of class domination. The persistence of their established habitus, meritocratic rationality and imaginaries drives them to compartmentalise their experience of the elite university - to engage primarily academically and side-line the social aspects. This way of engaging with the elite university reinforces their 'onedimensionality' and enhances the (relative) disadvantages and risks they will confront in the future in un-meritocratic environments (their employment choices are mentioned as an example in Authors, 2019a, p.10).

However, this paper will focus on six cases of 'counter-evidence' - workingclass 'exceptions' who do participate in forms of social life at university (see the Table 1 and Table 2 for details) - and they appear to change the consequences of meritocratic disciplines and transcend this form of class domination. The six cases represent 'critical cases in testing a well-formulated theory' (Yin, 2009), which in many ways open new possibilities for thinking about class reproduction. We divide the six respondents into two groups (the adaptive group and the transcending group) based on our data analysis and we begin with the adaptive group. 
Table 1. Brief introduction of the six cases

\begin{tabular}{|c|c|c|c|c|}
\hline & Gender & Region of origins & Occupations of Parents & Subject of studies at university \\
\hline \multicolumn{5}{|c|}{ Adaptive reflexivity } \\
\hline Xiao Li & $\mathrm{F}$ & Village & Father: decorator; Mother: mill worker & History of Art \\
\hline Yun Jiang & $\mathrm{F}$ & Village & Father and mother: peasants & Environmental Management \\
\hline Zhen Liang & M & Town & Father: used to be a mineworker, then taxi driver; Mother: cashier & Material Science \\
\hline \multicolumn{5}{|c|}{ Transcending reflexivity } \\
\hline Xing Guo & M & Town & Father: foreman of workers in a factory; Mother: nurse supervisor & Electronic Engineering \\
\hline Ye Lin & $\mathrm{F}$ & City & Father and mother: factory workers & Translation \\
\hline Yifan Yang & M & City & Father: bank clerk; Mother: self-owned print room & Electronic Engineering \\
\hline
\end{tabular}

Notes:

1. None of the parents of the six respondents received higher education.

2. The occupations of Xing Guo's mother and Yifan Yang's father are ambiguous to be defined as working-class according to the social class classification to which we refer (Liu, 2018; Lu, 2002). We have explained the case of Yifan Yang in Note 2 of this paper. Xing Guo comes from a town in the rural-urban fringe in Northeast China (economically under-developed) and he reported difficult family economic conditions in the interviews. Considering the economic condition of the region of his origins and his family, we include him in our sample. 
Table 2. Social experience at school and at university and employment destination

\begin{tabular}{|c|c|c|c|c|c|}
\hline & $\begin{array}{c}\text { School } \\
\text { Experience }\end{array}$ & $\begin{array}{l}\text { Extra-curricular } \\
\text { experience at University }\end{array}$ & $\begin{array}{c}\text { Internships and work } \\
\text { experience }\end{array}$ & $\begin{array}{l}\text { Overseas study } \\
\text { experience }\end{array}$ & Employment destination \\
\hline \multicolumn{6}{|c|}{ Adaptive reflexivity } \\
\hline Xiao Li & $\begin{array}{l}\text { No reported social } \\
\text { experience }\end{array}$ & $\begin{array}{l}\text { No reported ECA } \\
\text { experience }\end{array}$ & $\begin{array}{l}\text { University Psychological } \\
\text { Counselling Services Office; } \\
\text { running an online education } \\
\text { company with her boyfriend }\end{array}$ & $\begin{array}{l}\text { No reported overseas study } \\
\text { experience }\end{array}$ & $\begin{array}{l}\text { Online education entrepreneur } \\
\text { (working with her husband) }\end{array}$ \\
\hline Yun Jiang & Idem & Idem & $\begin{array}{l}\text { A leading human resources } \\
\text { company in China; Morgan Stanley }\end{array}$ & $\begin{array}{l}\text { Summer exchange to the } \\
\text { University of Hong Kong }\end{array}$ & $\begin{array}{c}\text { Headhunter in a Chinese leading } \\
\text { human resources company }\end{array}$ \\
\hline Zhen Liang & Idem & $\begin{array}{l}\text { Leader at the University } \\
\text { Student Support Center; } \\
\text { Guitar and piano interest } \\
\text { groups; Car racing society }\end{array}$ & $\begin{array}{l}\text { General Motors; Mercer; A.T. } \\
\text { Kearney; two leading Chinese } \\
\text { finance companies }\end{array}$ & $\begin{array}{c}\text { Summer exchange to the } \\
\text { National Tsinghua } \\
\text { University }\end{array}$ & $\begin{array}{l}\text { Financial analyst in a Chinese } \\
\text { leading finance company }\end{array}$ \\
\hline \multicolumn{6}{|c|}{ Transcending reflexivity } \\
\hline Xing Guo & $\begin{array}{l}\text { President of SU; } \\
\text { coordinator of the } \\
\text { school radio station }\end{array}$ & $\begin{array}{l}\text { President of SU in his } \\
\text { department }\end{array}$ & University Public Relations Office & $\begin{array}{l}\text { No reported overseas study } \\
\text { experience }\end{array}$ & $\begin{array}{l}\text { Senior government official } \\
\text { trainee }\end{array}$ \\
\hline Ye Lin & $\begin{array}{l}\text { President of SU } \\
\text { and the Model } \\
\text { United Nations } \\
\text { Society }\end{array}$ & $\begin{array}{l}\text { President of the Abstract } \\
\text { Art Society }\end{array}$ & $\begin{array}{l}\text { McCann Erickson; a fashion design } \\
\text { start-up; working with a famous } \\
\text { independent curator on two } \\
\text { exhibition projects }\end{array}$ & $\begin{array}{l}\text { One-year student exchange } \\
\text { to the University of } \\
\text { Washington in St. Louis }\end{array}$ & Interaction designer in L.A. \\
\hline Yifan Yang & $\begin{array}{l}\text { School basketball } \\
\text { team player }\end{array}$ & $\begin{array}{l}\text { Captain of the university } \\
\text { basketball team }\end{array}$ & $\begin{array}{l}\text { A leading Chinese private equity } \\
\text { fund company }\end{array}$ & $\begin{array}{l}\text { No reported overseas study } \\
\text { experience }\end{array}$ & $\begin{array}{c}\text { Financial analyst in a Chinese } \\
\text { leading private equity fund } \\
\text { company }\end{array}$ \\
\hline
\end{tabular}




\section{Adaptive reflexivity: submission as resistance, resistance as deep submission}

As can be seen from Table 2, the adaptive group appear to be totally committed to high levels of examination performance at school with little accumulation of social experience and skills, similar to the case for most of the other respondents (11/17) who have been discussed elsewhere (Authors, 2019a). However, the adaptive group are latterly able to change their perspective to experience university more fully, rather than continuing to obsessively invest in academic performance. The adaptive group seem to develop a more detached and reflexive attitude towards school culture and its meritocratic disciplines compared with most of the other respondents. This reflexivity is articulated by $\mathrm{Xiao} \mathrm{Li}$ :

I was cynical (at school). The stuff in the Politics textbooks is pretentious. Why should I spend so much time in reciting it? It's annoying. But I needed performance, I needed the position in the rankings, I needed Gaokao (national college entrance examination in China). So I forced myself to work hard on studies. I was not studying all the time. I went to the library to read what I liked. I was reading Nietzsche and Guoping Zhou (a famous writer in China and a researcher on Nietzsche). It was kind of a way of resisting.

Although Xiao Li found the performance-centred culture of her school irritating and she disliked working hard towards high grades, she forced herself to work hard as she 'needed' to succeed. Academic performance for the adaptive group is a means, a tool, towards the achievement of other goals, rather than 'a purpose to live in the world' articulated by most of the other respondents (Authors, 2019b). Therefore, in some 
respects, it is easier for the adaptive group to shift perspective and change their social investment strategy when they confront elite university.

The reflexive orientation demonstrated by the adaptive group indicates different degrees of submission to meritocratic disciplines and the related form of class domination among our respondents and suggests different possibilities to change the consequences of domination. The reflexivity of the adaptive group is described very appropriately by Giroux's extension of the concept of resistance. Giroux (1983) discussed the weakness of resistance theories in that they focus primarily on overt oppositional acts and ignore less obvious behaviours. As he comments, 'what resistance theorists have failed to acknowledge is that some students are able to see through the lies and promises of the dominant school ideology but decide not to translate this insight into extreme forms of rebelliousness' (Giroux, 1983, p. 288). In some cases, the rationality that informs such a response may be understood in that it 'gives them the power to reject the system on a level that will not make them powerless to protest it in the future' (Giroux, 1983, p. 288). Xiao Li's account in the above demonstrates some aspects of such a rationality. She was reluctant to fully accept the performance-centred culture and adopted a certain form of resistance, but in a manner that would not threaten her school career and her chances of a 'good life' through progress in the education system.

The certain degree of reflexivity evident among the adaptive group shows the 'transformative potentials' (Mills, 2008, p.82) of habitus - while on the one hand they have been subject for many years to the meritocratic disciplines of schooling, dedicating 
themselves to maximising their examination performance, on the other hand they retain a 'conscious rationality', which enables them to 'recognise the possibilities for action' and 'act in ways to transform situations' (Mills, 2008). However, the adaptive group, constrained by the resources on which they can draw (see the comparison with the transcending group in the next section), display their reflexivity in the form of reflexive awareness and seem unable to turn this reflexive awareness into reflexive action.

Also, the reflexive distance evident on the part of the adaptive group is to school culture or the form of meritocracy in schools, rather than to meritocracy itself. The adaptive group, like most of the other respondents, continue to believe deeply in meritocracy, as exampled by the account below by Zhen Liang. He still demonstrates a clear tendency to make evaluations of people and things using meritocratic standards:

I thought employees in consultancy firms should all be graduates from top universities. That company was different. The staff members were not so excellent. I didn't see that the firm cared about the reputation of the institutions from which they graduated. Not many of the staff graduated from top universities. There is a hierarchy in any field with excellent players at the top. Excellent industries would have the best resources and would attract the most talented people. I couldn't feel that kind of excellence in that firm.

The quality of the degree and the reputation of the university are used as major criteria to judge whether others are 'excellent' or not. Zhen Liang and many other participants reported explicitly that they liked to make friends with such 'excellent' people. They 
define 'excellence' often in terms of IQ, hard work and a university degree, things positively evaluated by meritocratic standards.

The problems that arise for our respondents when they strongly hold on to their meritocratic commitments are multifaceted. On the one hand, they are more likely to become distanced from their working-class parents, relatives and local community, who are unlikely to be defined as 'excellent' and 'successful' within a meritocratic evaluation system. Most of our respondents said, 'I can't go back', or 'I can't imagine I would go back after university'. On the other hand, the pursuit of 'excellence' and the achievement of upward social mobility are so single-minded, that they are distanced from possibility of education as a site of care of the self (Ball, 2016) or self-fulfilment. While for the adaptive group, maintaining a level of excellent performance is not the 'purpose to live in the world', striving to be an 'excellent' person is. The 'excellence' they are pursuing is often defined by meritocracy and by different forms of meritocracy in different fields, which is in turn defined as academic performance at school, an instrumental engagement in extra-curricular activities at university and high status, high-earning positions at work. There is no 'self' for its own sake in their striving for excellence. In this sense, they are not transcending the discipline of meritocracy or this symbolic domination of class; they are adapting to the different forms of symbolic domination in different contexts and they are subjects of a deeper and hidden symbolic domination. 


\section{Transcending reflexivity: possibilities and conditions for self-emancipation}

The adaptive group demonstrates a reflexive attitude towards school culture, while the transcending group that will be discussed in this section presents not only a reflexive attitude but also actual work done on themselves - a deliberate effort to address the consequences of meritocratic disciplines and class domination. The variations in the degree of reflexivity between the adaptive group and the transcending group relate less to their willingness and abilities to work on themselves (the adaptive group also shows much willingness to work on themselves and abilities to make use of resources, as will be seen later in this section) and more to the variations in capitals they possess to support such self-work. This illustrates what we call here the 'contingency' of reflexivity - the relation of reflexivity to capital and to history.

In order to demonstrate the antecedent and accumulated effects of reflexivity development in the educational trajectory, we use Ye Lin as the illustrative case, with extracts from the other two participants in the transcending group as supporting data.

\section{Conditions for developing a 'toned habitus'}

The transcending group also display very high-level reflexivity that enables them to recognise the influence of class on their 'dispositions' and the limitations imposed on them by the meritocratic disciplines of schooling. Furthermore, they make use of resources outside home to work on the limitations. Their habitus is restructured and 
restructuring by their deliberate efforts and their different modes of engagement with school, which evolves into what we term as 'toned habitus' (see below).

Thus, the transcending group are not completely dedicated to working on their performance at school, and their self-worth, imagined future and possibilities are not limited by meritocratic imaginaries (see the comparison with other respondents in Authors, 2019b). Ye Lin tends to define her 'exceptionality' by drawing on her personal interests and skills developed in painting rather than by referring to the high-achieving student identity. She had begun to enjoy painting in kindergarten, stating, 'I was very introverted. I didn't speak to other kids and I didn't like to take a nap at noon as required by school. So when they were sleeping, I sat there and painted'. Her parents (both factory workers with no higher education) paid for her to attend painting weekend classes, which lasted until she was in Year 5 at primary school, when her family could no longer afford those classes. After that, she learnt painting online by herself and then became interested in design. Here we can see the significance of parenting in contributing to her development of a personal interest, whereas the other two participants in the transcending group found and pursued their personal interests themselves - basketball for Yifan Yang and reading for Xing Guo.

Ye Lin experienced various forms of habitus dislocation when she moved from the countryside of Taiyuan (the capital city of Shanxi Province) to the city centre to attend junior school. Based on her painting skills, not only did she overcome these dislocations and fit in well at junior school, but she also made friends and began to 
acquire forms of dominant cultural capital by learning from these friends, as she explained:

I liked to make friends who were different from me, who knew what I didn't know. For example, if he/she had beautiful handwriting, I would observe how he/she practiced. My handwriting became good at that time. And also from that time on, I began to know classical music. My friends lent me CDs. And friends who knew Beijing Opera sang to me and taught me about The Drunken Beauty or Taking Tiger Mountain (two classic Beijing Operas). And with my friends, I began to write diaries, read novels and learn literature.

There is what we might identify as a conversion of social capital into cultural capital in Ye Lin's account, which contributes to the modification and restructuring of the 'structured structure' of her habitus formed within the working-class family and by meritocratic disciplines at school. The purposive accumulation of social capital through peer relationships and benefitting from such accumulation is also confirmed in Guan and James's study (2019) of adult higher education students in China.

An analysis of Ye Lin's narrative and comparisons with the narratives of some other participants highlights two conditions for the success of this conversion and Ye Lin's acquisition of middle-class cultural capital - involving such things as access to operas, classical music and literature. One is that Ye Lin meets and befriends middleclass students at school. The opportunities to meet such students at school are not equally distributed among our respondents. Location plays an important role, which is evident from the comparison between Ye Lin and Xiao Li. Ye Lin is from a capital city 
so she has many middle-class friends at school, while Xiao Li is from a small village and even when she moved from a village to a town for junior and senior school, there were very few middle-class students; 'there are not many differences between a village and a town' she said.

A second condition for Ye Lin's conversion of social capital into cultural capital is her reflexivity. She observed, thought about and consciously learnt from her friends. According to Bourdieu (1986), accumulation of capital, that is, economic capital, social capital and especially cultural capital, needs the investment of time and effort and cultural capital requires particular time and effort. Ye Lin made deliberate and strategic efforts to acquire middle-class cultural capital from her friends, to make herself more like them.

At the same time, Ye Lin worked on her working-class habitus, deliberately addressing her lack of social skills - she identified this as the biggest influence of her family background. Rather than accepting her supposed 'introverted personality' 'make adaptation to deprivation' (Authors, 2018; Bourdieu, 1990), she chose to work on herself. She observed classmates at junior school, reflected on her situation and worked to improve her social skills, as she described:

The impact of family background on my social ability was really significant. I didn't know what games I could play with them at dinner, what restaurants and what places we should go to. I was learning by observing them. My classmates were very nice. They didn't feel there was any problem with me. I only followed them at the beginning and then I started to organise a get-together. 
The same approach to working on the self appears in the accounts of the other two 'transcending' students as well. Learning from 'different others' constitutes one way for them to develop a 'toned habitus'; the other is to participate in social activities at school. Ye Lin attended the students' union in her senior school and the Model United Nations Society ${ }^{3}$, later becoming a leader in both societies. Xing Guo was the president of the student union of his senior school and was also responsible for organising the school radio station. Yifan Yang was in the school basketball team. They were all highachieving students at school but at the same time they were extensively involved in social activities and they developed more than just academic competencies. This had an impact on their university experience, which will be seen later.

The accounts of the transcending group highlight the possibility of changing a habitus by a reflexive awareness of 'the conditionings undergone' and a strategic and long-time effort to 'counter their effects', as suggested by Bourdieu (1999b, p. 340). By referring to the case of Farida in The Weight of the World (Bourdieu, 1999a, p. 583589), Sayer (2005) also suggests the possibility of changing a habitus deliberately by 'repeated practice aimed at the embodiment of new dispositions' (p.30).

However, the accounts of the transcending group also draw attention to the need for certain social conditions to pertain for such changes to habitus to occur. These conditions are not equally satisfied across our sample, as we have seen in the comparison between Xiao Li and Ye Lin. In fact, for the majority of our respondents

\footnotetext{
3 A social group in which students role-play national ambassadors in the United Nations to debate and discuss global issues
} 
who are from the countryside or small towns, there are few possibilities for them to meet middle-class students and there are few extra-curricular activities they can access. All three respondents in the transcending group had senior school education in the city and two of them are from the provincial capital. In terms of their reflexive awareness all three came from families who were relatively 'well off' economically and socially compared with the others in our sample. Yifan Yang is one of only two upper workingclass students in our study, Ye Lin had middle-class relatives and Xing Guo's mother worked as a nurse supervisor in the hospital and his father worked as a foreman of factory workers. Jackson and Marsden's (1966) study of 'successful' working class students also showed that the students with middle-class relatives or fathers working as foremen were more likely to achieve at school and more likely to continue tertiary education after grammar school. The participants who can meet both conditions are few in number in our study. For example, Xiang He, the other upper working-class student in our study, studied in town schools where he found it difficult to meet middle-class students. The participants who can work on themselves and who developed a 'toned habitus' at school are the lucky within the lucky and the exceptions within exceptions in our study.

The narratives of the transcending group offer some evidence of what Rancière (1991) calls 'intelligence' and what Sayer (2005) calls 'mundane reflexivity', but this 'pre-social' reflexivity needs certain conditions to survive and to operate, as we have seen in the conditions for developing a 'toned habitus'. Reflexivity relates to and is contingent on an insidious form of social inequality; it is also reproduced on the basis 
of this form of inequality, as evident in the university experiences of the transcending group.

\section{Experience at university: further work upon the self}

Bringing a 'toned habitus' to university, the transcending group report a lesser sense of dislocation and display less evidence of self-exclusion, rather they work further on themselves and accumulate more middle-class cultural capital.

We have seen in the last section how Ye Lin improved her social skills by learning from school friends. In the following account by Xing Guo, we can see the importance of another kind of social capital - tutors:

The director of the office I worked for at university was important in helping me to improve myself. She asked me to organise the orientation party (which he listed as the most important thing for him at university). She would point out my mistakes very directly. For example, she would say, your outfit today was inappropriate. Socks shouldn't be white. She told me where the label should be pointed and how you should pour when you made tea for guests.

The tutor in Xing Guo's account corrected his dress and manners to make him more 'professional' or, in another sense, more 'middle-class'. These are the things Xing Guo did not learn at home from his working-class parents. He is changing his dispositions under the guidance of the tutor. The account above also offers some sense of why he has less of a tendency towards self-exclusion from student societies - he is encouraged and supported by the tutor. Yet, implicit in the account of Xing Guo is a link between 
his socialisation at school and his changes and experience while at university. He has more confidence and accumulation of skills at his disposal than many of the other participants in our study. He learnt how to get along with teachers and with those in positions of authority while working as the president at the student union at his senior school. He draws on his already well-developed dispositions to work further on himself. The 'toned habitus' delivers 'unconscious' advantages and privileges for Xing Guo.

We are not suggesting that only the transcending group work on themselves at university; some other participants described similar efforts, Yun Jiang for example:

Morgan Stanley indeed had their way of selecting and training people and the people they selected could represent the image of their company. The head of our campus recruiting team was such a person. He was very gentlemanly, had a cheerful way of talking, and could deliver a very clear message. He always had manners. This was who I wanted to be. I wanted to change myself little by little.

Yun Jiang observed, reflected and worked on herself. She observed the manners of her colleagues and learned from their behaviours. With an absence of a concrete role model as to what is 'middle-class' in a working-class family, her colleague at Morgan Stanley became the concrete objective, standard and role model that she could work towards. Also friends at university are another important factor enabling Yun Jiang to work on herself and acquire middle-class dispositions and cultural capital, such as going to concerts and exhibitions and wearing certain clothes and make-up.

Yun Jiang's account supports the argument we put forward earlier in this section that some respondents may have reflexive awareness of their working-class dispositions 
and a willingness to work on themselves at school, but they do not have the conditions to realise this willingness until they get to university. The ability to work on the self by using outside resources is like an accumulation of capital based on a history of investing and working - social differences turned into social advantages. Although some other participants can work on themselves at university, the transcending group appear able to work on themselves to a greater degree, with more competencies and fewer difficulties. Ye Lin's reflexivity is like an athlete's muscles, which have been trained and toned for many years (and this is why we use the term, 'toned habitus'). By learning from her friends at university, Ye Lin devised a sophisticated plan for her overseas studies:

Carnegie Mellon is my first choice as their educational ideas are very prescient. They integrated the ideas of business and computer science with design since 1990s, but until now the UI design in China is still unsophisticated. Online forums are one source for me to learn information and the other one is my friends, friends from many other subjects, like Computer Science, Digital Effects, Philosophy, Architecture, Economics, Mathematics and so on.

She took a gap year after the final year at university in order to better prepare these applications. In order to have a solid knowledge base and skill training in user interaction design, she found and attended a UI designer's tutorial course (self-paid) outside campus and she also took a post-graduate course on User Interaction Design at Tongji University (another prestigious university in Shanghai that is very strong in architecture and design). Meanwhile she completed coding courses provided by UCL 
on Coursera. She demonstrates a very clear ability to use her initiative and to be resourceful and flexible.

As Bourdieu commented, regarding the ability to make rational economic decisions, 'the propensity to acquire it depends on the chances of using it successfully' (1990, p. 64). The ability to be reflexive is also based on the experience of being successful in having used reflexivity before. In years of using reflexivity to make the best of the resources outside home, reflexivity is practised adeptly by Ye Lin. The enhancement of reflexivity and working further on the self at university can also be seen in the cases of Xing Guo and Yifan Yang. While one exceptional aspect of Ye Lin's account is that her reflexive dispositions are not only used in working on herself to embody middle-class dispositions and to approach the middle class, but are also evident in her 'commencement':

It means the commencement of self-consciousness. We are doing what we are told to do before Gaokao. We are doing the same things, evaluated by the same standards, by our examination performance. When you go to university, you may be in a subject that you don't like, like me. You are struggling at university and then you know what you like and what you don't like. This is the 'commencement' for many Chinese students.

This is not the case for most of our respondents who continue to devote the majority of their time to examination performance at university (Authors, 2019a), or use reflexive dispositions to work on themselves in order to embody middle-class dispositions and to become middle-class. Personal interest, pursuit of a passion and self-fulfilment based 
on a 'commencement of self-consciousness' are rarely seen in the life stories in our study. Apart from Ye Lin, only Xiao Li mentioned her personal interest in psychology and continued to work in this field after her post-graduate studies. At the point of making career choices, Yifan Yang prioritised his personal interest rather than pursuing a high salary (he developed an interest in finance through an internship and he chose to work in finance rather than in the artificial intelligence industry, although the latter is more directly related to his subject studies and offers a higher salary).

\section{Conclusion: self-emancipation based on the nuanced production and reproduction}

\section{of social inequality}

Bourdieu and other reproduction theorists are often criticised for presenting class domination as inexorable and deterministic with very little space for reflexivity and transcendence, and they are accused of perpetuating a view of 'the dominated' as inadequate and lacking reflexivity (Hattam and Smyth, 2014). This paper, albeit drawing on a very small sample, offers evidence of various degrees of reflexivity among a group of working-class Chinese students. Some appear to submit to class domination but at the same time maintain a sense of detachment from it, as in the case of the adaptive group. Some use strategies to avoid subjection and make use of available resources to work on the self and to achieve some kind of self-emancipation. Aspects of class domination may well be hidden and persistent within the educational and social experience of these students, but their 'mundane reflexivity' (Sayer, 2005) can offer the possibility of 'escape'. Although it is 'uneven' and 'piecemeal' (Adams, 2006, p.521), 
there is always a hope or indeed the possibility of achieving transcendence of class domination. The notion of 'toned habitus' clearly indicates the role and the prevalence of reflexivity (not only in 'crisis situations' as argued by some authors) in changing and challenging an established habitus and the role of 'practice' (Bourdieu, 1990), especially socialisation at school, in enabling change and challenge.

However, the reflexivity identified in this paper has different forms and degrees - reflexive awareness versus reflexive action, adaptive reflexivity versus transcending reflexivity. These variations are not simply differences in motivations, aspirations, and competencies but are related very directly to the unequal distribution of capitals. The transcending group - the 'reflexive winners' (Lash and Urry, 1994) depicted in this study - with their 'toned habitus' do achieve an extent of transcendence of class domination. They are relatively privileged in terms of their access to relevant capitals and social conditions. In this sense, the triumph over class history and background achieved by the working-class 'exceptions within exceptions', constitutes an illusion of the possibility of self-emancipation, an illusion that is deeply implicated in the production and reproduction of inequality. Capital still matters, but matters in nuanced and subtle ways, making possible different forms of and degrees of reflexivity and producing a stratification based on different reflexive dispositions. This is to say, as Adams (2006) concludes his essay, JinJquoting Bauman (1998, p.86), 'all of us are doomed to the life of choices, but not all of us have the means to be choosers'. 


\section{References}

Adams, M. (2006) Hybridizing habitus and reflexivity: towards an understanding of contemporary identity? Sociology, 40 (3), 511-528.

Adkins, L. (2002) Revisions: Gender and Sexuality in Late Modernity (Buckingham, Open University Press).

Archer, M. (2000) Being Human: The Problem of Agency (Cambridge, Cambridge University Press).

Aries, E. and Seider, M. (2005) The interactive relationship between class identity and the college experience: the case of lower income students, Qualitative Sociology, $28(4), 419-443$.

Authors. (2018) Is it possible to transcend class domination? A life story study of working-class students at elite universities in China, Details omitted for peer review.

Authors. (2019a) Precarious success and the conspiracy of reflexivity: questioning 'habitus transformation' of working-class students at elite universities, Details omitted for peer review.

Authors. (2019b) Meritocracy, social mobility and a new form of class domination, Manuscript submitted for publication.

Ball, S.J. (2016) Subjectivity as a site of struggle: refusing neoliberalism? British Journal of Sociology of Education, 37 (8), 1129 - 1146. 
Ball, S. J., Davies, J., David, M., and Reay, D. (2002) 'Classification' and 'judgement': social class and the 'cognitive structures' of choice of higher education, British Journal of Sociology of Education, 23 (1), 51-72.

Bathmaker, A-M., Ingram, N., and Waller, R. (2013) Higher education, social class and the mobilisation of capitals: recognising and playing the game, British Journal of Sociology of Education, 34 (5-6), 723-743.

Bauman, Z. (1998) Globalisation (Cambridge, Polity Press).

Bell, D. (2016) The China Model: Political Meritocracy and the Limits of Democracy (New Jersey, Princeton University Press).

Boltanski, L. and Chiapello, E. (2007) The New Spirit of Capitalism (London, Verso Books).

Bourdieu, P. (1986) The forms of capital. In J. Richardson (Ed) Handbook of Theory and Research for the Sociology of Education. (New York, Greenwood), 241258.

Bourdieu, P. (1990) The Logic of Practice (Cambridge, Polity Press).

Bourdieu, P. (1996) The State Nobility (Cambridge, Polity Press).

Bourdieu, P. (1999a) The Weight of the World: Social Suffering in Contemporary Society (Cambridge, Polity Press).

Bourdieu, P. (1999b) Scattered remarks, European Journal of Social Theory, 2 (3), $334-340$.

Bourdieu, P. and Passeron, J-C. (1990) Reproduction in Education, Society and Culture (London, Sage). 
Bourdieu, P. and Wacquant, L.D. (1992) An Invitation to Reflexive Sociology (Chicago, University of Chicago Press).

Brown, P., Lauder, H., and Ashton, D. (2011) The Global Auction, the Broken Promises of Education, Jobs and Incomes (Oxford, Oxford University Press).

Elman, B.A. (2013) Civil Examinations and Meritocracy in Late Imperial China (Cambridge, MA, Harvard University Press).

Friedman, S. (2016) Habitus clivé and the emotional imprint of social mobility. Sociological Review, 64 (1), 129-147.

Giroux, H. (1983) Theories of reproduction and resistance in the new sociology of education: a critical analysis, Harvard Educational Review, 53 (3), 257-293.

Granfield, R. (1991) Making it by faking it: working-class students in an elite academic environment, Journal of Contemporary Ethnography, 20 (3), 331-351.

Gronow, A. (2008) The over- or the undersocialized conception of man? Practice theory and the problem of intersujectivity, Sociology, 42 (2), 243-259.

Guan, S. and James, F. (2019) Staying afloat via guanxi: student networks, social capital and inequality in Chinese adult higher education, British Journal of Educational Studies, Advance online publication. doi:

\section{$\underline{10.1080 / 00071005.2019 .1618788}$}

Hattam, R. and Smyth, J. (2014) Thinking past educational disadvantage, and theories of reproduction, Sociology, 49 (2), 270-286.

Hurst, A.L. (2010) The Burden of Academic Success: Loyalists, Renegades, and Double Agents (Lanham, Lexington Books). 
Jack, A. (2016) (No) Harm in asking: class, acquired cultural capital, and academic engagement at an elite university, Sociology of Education, 89 (1), 1-19.

Jackson, B. and Marsden, D. (1966) Education and the Working Class (Harmondsworth, Penguin Books).

Karabel, J. (2005) The Chosen: the Hidden History of Admission and Exclusion at Harvard, Yale and Princeton (Boston, Houghton Miffen Company).

Keane, E. (2011) Distancing to self-protect: the perpetuation of inequality in higher education through socio-relational dis/engagement, British Journal of Sociology of Education, 32 (3), 449-466.

Lauder, H. and Hughes, D. (1999) Trading in Futures: why Markets in Education don't Work (Buckingham, Open University Press).

Lareau, A. (2011) Unequal Childhoods: Class, Race and Family life (2nd edn) (Berkeley, University of California Press).

Lash, S. and Urry, J. (1994) Economies of Signs and Space (London, Sage).

Lehmann, W. (2009) Becoming middle class: how working-class university students draw and transgress moral class boundaries, Sociology, 43 (4): 631-647.

Lehmann, W. (2012) Extra-credential experiences and social closure: working-class students at university, British Educational Research Journal, 38 (2), 203-218.

Lehmann, W. (2013) Habitus transformation and hidden injuries: successful workingclass university students, Sociology of Education, 87(1), 1-15.

Li, H. (2013) Rural students' experiences in a Chinese elite university: capital, habitus and practices, British Journal of Sociology of Education, 34 (5-06), 829-847. 
Li, L.L. and Qin, G.Q. (2016) An Analysis of Class Structure in Modern China (Beijing, China Renmin University Press).

Liu, X. (2018) Coordination, domination and income distribution: the structure of social stratification in transitional China, Social Science Research, (1), 89 - 116.

Lu, X.Y. (2002) A Report on the Social Classes in Contemporary China (Beijing, Social Sciences Academic Press).

Marcuse, H. (1991) One-Dimensional Man: Studies in the Ideology of Advanced Industrial Society (2nd edn) (Boston, Beacon Press).

McNay, L. (1999) Gender, habitus and the field: Pierre Bourdieu and the limits of reflexivity, Theory, Culture and Society, 16 (1), 95-117.

Mills, C. (2008) Reproduction and transformation of inequalities in schooling: the transformative potential of the theoretical constructs of Bourdieu, British Journal of Sociology of Education, 29 (1), 79-89.

Postiglione, G.A., Xie, A., Jung, J., \& Hong, Y. (2017) Rural students in a Chinese toptier university: family background, school effects, and academic performance, Chinese Education \& Society, 50 (2), 63-74.

Putnam, R.D. (2015) Our Kids: The American Dream in Crisis (New York, Simon \& Schuster).

Rancière, J. (1991) The Ignorant Schoolmaster: Five Lessons in Intellectual Emancipation (Stanford, Stanford University Press). 
Reay, D. (2004) 'It's all becoming a habitus': beyond the habitual use of habitus in educational research, British Journal of Sociology of Education, 25 (4), 431444.

Reay, D., Crozier, G., and Clayton, J. (2009) 'Strangers in paradise'? Working-class students in elite universities, Sociology, 43 (6), 1103-1121.

Reay, D., David, M., and Ball, S. J. (2005) Degrees of Choice: Class, Race, Gender and Higher Education (Stroke on Trent, Trentham Books).

Sayer, A. (2005) The Moral Significance of Class (Cambridge, Cambridge University Press).

Skeggs, B. (1997) Formations of Class and Gender (London, Sage).

Stuber, J. (2011) Inside the College Gates: How Class and Culture Matter in Higher Education (Lanham, Lexington Books).

Sweetman, P. (2003) Twenty-first century dis-ease? Habitual reflexivity or the reflexive habitus, Sociological Review, 51 (4), 528-549.

Thornberg, R. (2012) Informed Grounded Theory, Scandinavian Journal of Educational Research, 56 (3), 243-259.

Tomlinson, M. (2008) 'The degree is not enough': students' perceptions of the role of higher education credentials for graduate work and employability, British Journal of Sociology of Education, 29 (1), 49-61.

Wacquant, L. D. (1993) From ruling class to field of power: an interview with Pierre Bourdieu on La Noblesse d'État, Theory, Culture \& Society, 10 (3), 19-44. 
Xie, A. (2016) Rural students in China's elite universities: social mobility and habitus transformation, Educational Research, (11), 74-81.

Xie, A., Hong, Y., Kuang, H., \& Postiglione, G.A. (2018). Cultural Capital Deficiency as challenges: rural students in elite universities, Peking University Education Review, 16 (4), 45-64.

Yin, R.K. (2009) Case Study Research: Design and Methods (4th edn) (London, Sage).

Zimdars, A. (2016) Meritocracy and the University: Selective Admission in England and the United States (London, Bloomsbury Publishing). 